\title{
Monopoly Power of the Medical School Market and High Incomes of U.S. Physicians
}

\author{
J.J. Phelan ${ }^{1}$, A.C. Arize ${ }^{2}$, J. Malindretos ${ }^{3}$, P. Anastasopoulos ${ }^{4}$, L. Verzani $^{5}$
}

\begin{abstract}
:
We expect the incomes of physicians to remain high in the next decades. Using the latest published physician income data (2015) we calculated the weighted median income of U.S. physicians and the net present value (NPV) of an investment in physician education.

We estimated the NPV assuming that the physicians training began in 2007 and their practice would commence in 2015. We estimated the NPV of the lifetime earnings of a physician based on the median income of all physicians in the sample to be between $\$ 7.1$ and $\$ 7.3$ million.

This finding of high NPV's is consistent with almost all earlier studies of this kind. Physicians continue to experience relatively high incomes and very slow increases in the number of new graduates. We expect an excess demand for positions in medical colleges to continue.
\end{abstract}

Our findings with respect to the incomes of non-primary physicians (surgeons, radiologist and cardiologists), indicate will continue to be much higher than those of primary physicians.

There are strong evidence suggesting this is because of blockages in physician residency openings in these non-primary fields of medicine.

\footnotetext{
${ }^{1}$ Dpt of Economics, University of New Haven, Formerly the Associate Exec Secretary to the Secretary of the US Department of Health and Human Services, 1981-1989.

${ }^{2}$ Dpt of Economics and Finance, College of Business, Texas A\&M.

${ }^{3}$ Dpt of Economics Finance and Global Business, Cotsakos College of Business, William Paterson University, e-mail: malindretos@wpu.edu

${ }^{4}$ Dpt of Economics, Finance and International Business, Silberman College of Business, Fairleigh Dickinson University.

${ }^{5}$ Dpt of Economics Finance and Global Business, Cotsakos College of Business, William Paterson University.
} 


\section{Introduction}

The recent public policy debate in the United States has focused on how to provide financial assistance to the approximately 30 million individuals in the population who currently lack health insurance through their employer. Unfortunately, the debate has focused mostly on the demand side of the health services market. For example, the Affordable Care Act (ACA) provided mandates on individuals and employers to purchase health insurance and provided some subsidies to help pay for this insurance. The Republican proposal to amend or repeal the ACA also focuses on the demand side of the market as well.

In this paper, the effort is to shed light on the supply of health services - specifically the services of physicians. The demand for physician services, and auxiliary health personnel, will likely increase due not only to the ACA but also to the aging of the population. We explore how the supply side of the market is likely to respond to increases in demand in the short and the long-run. Is the supply of physicians keeping up with the increased demand? While it is true the supply of physicians has increased over the past 10 to 15 years, it appears a large shortage remains. According to the American Association of Medical Colleges (AAMC), there is a shortage of physicians in the range of 62,000 to 95,000 in the U.S. over the next decade with one-third of practicing physicians over the age of 55. ${ }^{6}$ AAMC estimates the total demand for physicians to be approximately 930,000 in 2025 while the supply to be only 850,000 . A shortage of 80,000 physicians is very substantial when you realize the supply of new physicians is approximately 20,000 per year. While the number of applicants to medical colleges in 2015 increased by $6.2 \%$ compared to 2014, a large number of applicants were refused admission.

\section{Literature Review}

Most of the empirical work around rates of return on medical education indicate that an investment in a medical degree and subsequent residency training is very rewarding - especially when compared to many other professions such as the legal profession. Borad (2) calculated the net present values (NPV) of 25 medical specialties across 50 states using physician income date for 2013 and found all specialties to have a positive NPV's at a 5\% discount rate. The highest NPV was in Orthopedics, Urology and Cardiology specialties - all with NPV's over \$3 million. The lowest specialty was Infectious Disease with a NPV of $\$ 720,000$.

Roth $^{7}$ calculated the NPV and the internal rates of return (IRR) for 29 physician specialties using 2009 income. Roth found the IRR for all specialties (lowest: 11.1\% - Endocrinology and highest- 35.3\% - Radiology [non-invasive]) to be high. Roth

\footnotetext{
${ }^{6}$ AAMC report "New Research Confirms Looming Physician Shortage, April 5, 2016.

${ }^{7}$ Nicholas Roth, The Costs and Returns to Medical Education, 2013, (unpublished),

University of California, Berkeley.
} 
also found the NPVs to be similar to Borad. Based on 5\% discount rate, the highest NPV was in Radiation Oncology at $\$ 4.8$ million and the lowest in Endocrinology at $\$ 973,000$.

Nicholson ${ }^{8}$ estimated that the discounted present values of lifetime earnings in 1986 and 1998 of physicians in 9 specialties were very high especially for non-primary specialties. According to Nicholson:

"In 1986 the net present value of lifetime income ranged from \$2.6 million in family practice, pediatrics, and general internal medicine to $\$ 5.7$ million in orthopedic surgery. Physician lifetime income increased in real terms in all specialties between 1986 and 1992, and increased more substantially in the non-primary than primary care specialties." 9

The findings mentioned above are consistent with the findings of older studies such as the Burstein and Cromwell ${ }^{10}$ study which found high internal rates of return for the period 1967 and 1980. IRRs for all physicians, adjusted for longer work hours, were between $10.2 \%$ and $12.1 \%$ during this period. IRRs for specialist such as obstetricians/gynecologists and general surgeons between $13 \%$ and 14\%. All IRRs have risen substantially during the post Medicare/Medicaid period. IRRs for lawyers over this same period were approximately $7 \%$.

\section{The Data and the Model for Estimating Rates of Return for U.S. Physicians - 2015}

Physician incomes for 2015 were based on the latest survey conducted by Medical Group Management Association's (MGMA) Provider Compensation and Production Report, 2016. The MGMA received written survey responses from approximately 80,000 practicing physicians. The income data is for the calendar year of 2015 and includes all forms of compensation. According to the American Association of Medical Colleges (AAMC), there were 759,000 physicians treating patients in the United States in $2015^{11}$. Therefore, the response rate was approximately $10.5 \%{ }^{12}$.

Cost of Physician Training. The cost of education includes tuition, books and fees, and foregone income that medical students give up in order to attend medical college on a full time basis. All studies of this topic subtract from the cost side of the

\footnotetext{
${ }^{8}$ Sean Nicholson, Barriers to Entering Medical Specialties, September, 2003, The Wharton School, University of Pennsylvania and the National Bureau of Economic Research. ${ }^{9}$ pp 7-8.

${ }^{10}$ Phillip L. Burstein and Jerry Cromwell, Relative Incomes and Rates of Return for U.S. Physicians, Journal of Health Economics 4 (1985) 63-78.

${ }^{11}$ AAMC, 2016 Supply Data Report.

${ }^{12}$ Internal surveys will generally receive a $30-40 \%$ response rate (or more) on average, compared to an average 10-15\% response rate for external surveys according to SurveyGismo.
} 
equation the salaries residents receive for the 3 to 5 years they are in training. Besides resident incomes, however, the federal government subsidizes resident training in a significant way that is borne by taxpayers. The federal subsidy for the latest year available is approximately $\$ 15.5$ billion in $2012^{13}$. We propose to add this subsidy to resident income (or subtract it from the cost of training) because if this funding source were not made available, teaching and other hospitals, would have to either charge tuition to residents or find some other source of income to offset the loss of the subsidy.

\subsection{Weighted Average Medical College Tuition and Fees, AY 2008 thru 2011}

Because the most recent physician compensation data is for 2015, we used tuition rates based in 2007/8. We assumed the average length of medical school and residency training to be approximately four years each. Therefore, the initial year of the NPV calculations is $2007 / 8$, i.e., 8 years prior to 2015 . For example, a physician practicing in 2015 would have started paying tuition fees in a medical college in $2007 / 8$.

Regarding tuition and fees (including health insurance), we obtained our data for medical colleges from the AAMC for the academic year 2016/17, and we used the weighted average of three categories of tuition for the four years of the study from 2007/08 through 2010/11. The first category was tuition of private medical colleges, and the second and third categories were tuition of public institutions for out-of-state and in-state medical students.

We estimated the weights based on data of residence Matriculated students attending public medical colleges. We obtained this data from AAMC, FACTS: Applicants, Enrollment, Graduates, M.D.-Ph.D., and Residency Applicants. The percentage of matriculating students paying out-of-state tuition at public institutions was $16 \%$, while in-state tuition was $58 \%$. The percentage of students attending private medical college was $26 \%^{14}$.

\footnotetext{
${ }^{13}$ Committee on the Governance and Financing of Graduate Medical Education, Board on Health Care Services; Institute of Medicine, Graduate Medical Education That Meets the Nation's Health Needs, ed. Jill Eden, Donald Berwick, and Gail Wilensky (Washington, D.C.: National Academies Press, 2014.

${ }^{14}$ Data on the number of matriculating students at public and private medical colleges, by state of residence is not available for period 2007/8 thru 2010/11. As a result, we estimated the tuition weights based of the residence of matriculating students in the 2016/17 class. Thus, by calculating the weighted average tuition for that year, we assumed that the percentage of out-state/in-state matriculating students in 2007 - 2010 period is not significantly different from the 2016/17 period. Source: Table A-1: U.S. Medical School Application and Matriculants by School (type), State of Legal Residence, and Sex, 20162017, AAMC.
} 
The number of students entering private medical colleges in the fall of 2016 was 5,559; out-of- state students attending public colleges were 3,194; and in-state students attending public institutions were 12,277.

Table 1. U.S. Medical College Tuition ${ }^{15} 2007 / 8$ through 2010/11

Public Medical Colleges -Resident

$\begin{array}{llll}2007 / 8 & 2008 / 9 & 2009 / 10 & 2010 / 11 \\ \$ 21,828 & \$ 22,784 & \$ 24,778 & \$ 26,547 \\ \$ 41,081 & \$ 42,239 & \$ 44,908 & \$ 47,738 \\ \$ 41,033 & \$ 42,670 & \$ 44,426 & \$ 45,980 \\ \mathbf{\$ 2 9 , 9 0 2} & \$ 31,065 & \mathbf{\$ 3 3 , 1 0 7} & \$ \mathbf{3 4 , 9 9 0}\end{array}$

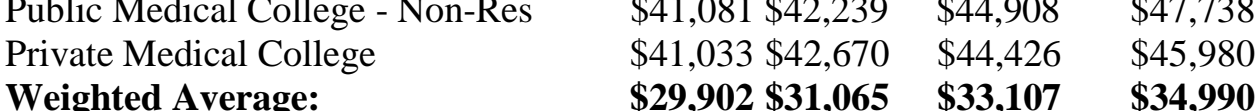

The first phase of calculating NPV is negative because we expect the medical student for the first four (4) years to have no income, to be paying tuition and has only an opportunity cost of foregone income. Average tuition and fee costs increased approximately $3 \%$ per year since 2013 . We assume tuition and fees will increase at this rate for the four years of medical school.

\subsection{Opportunity Cost of 4-Years of Medical College}

The average starting salaries for graduates of college in 2007/08 for various occupations were as follows ${ }^{16}$ :

Chemistry and Chemical Engineering

$\$ 60,054$

Economics

$\$ 51,631$

Finance

$\$ 47,905$

Liberal Arts
$\$ 30,502$

To be on the conservative side we have selected the average salary of Chemistry and Chemical Engineering graduates $(\$ 60,054)$ to represent the opportunity cost of a student entering in medical school in fall of 2007. The percent increase in engineering salary from the previous year was $7 \%$. It is unlikely that starting salaries for engineers will continue to increase at this rate every year. NACE reported that average starting salaries for all college graduates increased by $3.8 \%$ in 2016 over 2015 . We will assume this is the rate of increase in the opportunity cost per year while a student is in medical training through residency.

\section{Cost and Benefits of Graduate Medical Education (GME)}

\subsection{Cost Per Resident}

As stated above, a number of federal programs provide financial support to graduate medical residents. In order to be able to practice medicine in the U.S., a physician

\footnotetext{
${ }^{15}$ The data includes lab and other fees and health insurance.

${ }^{16}$ National Association of Colleges and Employers (NACE), fall 2007 Salary Survey. The data contained in NACE's fall 2007Salary Survey report.
} 
should have a license by completing a minimum of three years of GME. In 20142015, approximately 118,000 individual residents were in training including approximately 21,000 fellows ${ }^{17}$. The federal government finances almost $\$ 15$ billion per year for GME via the Medicaid, Medicare, and the Veteran's Administration programs. Private and other sources of funds provide an undertermined amount for GME to smaller or specialized medical institutions ${ }^{18}$. The latest information available indicates that there are approximately 118,000 residents in graduate medical training, not counting fellows ${ }^{19}$, in the academic year 2014/15. We estimate that federal and private funds subsidize the training of GMEs in the amount of approximately $\$ 181,700$ per year, per resident ${ }^{20}$. These public and private funds help pay for direct and indirect GME. For example, public funds go to pay for residency stipends, other direct medical training, as well offsetting administrative and GME medical faculty salaries.

\subsection{Revenue Generated by Residents}

Although it is costly to fund resident training, there is an offsetting financial benefit to patients and the training hospitals since resident physicians perform many medical procedures and services including patient management after completion of their first year of residency ${ }^{21}$. However, between the $2^{\text {nd }}$ and last year of their residency training residents can perform minor surgery and treat patients that generate revenue for the hospital. Stoller, Pratt, Stanek, Zelenock and Nazzal ${ }^{22}$, estimated the yearly revenue generated in assistant operative services, minor procedures, patient management, and independent consultations to be $\$ 94,872$ per resident per year.

\subsection{Net Subsidy for GME}

Depending on their specialty, it will take residents between 3 and 6 years to complete their training and become board certified. For Internists, Family Medicine, and Podiatrists typically takes 3 years to complete while others take 5 to 6 years (Surgery specialties, Cardiology). We calculated the weighted average number of

\footnotetext{
${ }^{17}$ U.S. Government Accountability Office, Graduate Medical Education: Trends in Training and Student Debt, 09-438R, May 4, 2009.

${ }^{18}$ Op. cit. Graduate Medical Education That Meets the Nation's Health Needs, p. 1 and Table 3.

${ }^{19}$ Fellows are graduate medical students who have completed their required residency training but continue on for a year or two for further research and training.

${ }^{20}$ Ben-Ari, R Robbins, S, Pindiprolu and A. Goodman, M.Ds estimated that the annual cost of training a resident in internal medicine in a large institution with 160 residents in 2013 was $\$ 181,737$ per year. The salary of residents $(\$ 66,000)$ and all other direct and indirect costs were included. Source: The Cost of Training Internal Medicine Residents in the U.S., Table 5. American Journal of Medicine, Vol 127, No. 10, October 2014.

${ }^{21}$ Most, if not all, states do not license a physician until they have completed one year of intership/residency and therefore hospitals cannot bill for their services during this period.

${ }^{22}$ Financial Contribution of Residents When Billing as "Junior Associates" in the "Surgical Firm". Stoller J, Pratt S, Stanek S, Zelenock G, Nazzal M, Journal of Surgical Education, 2016, Vol 73 (1), 85-94.
} 
years of residency training for the sample of physicians in our data set on salaries to be 4.1 years. Thus, the average public subsidy for a typical resident in internal medicine is approximately $\$ 726,800$ minus the financial contribution of $\$ 94,872$ for the second through the fourth year of residency. The net subsidy for resident training is as follows: $\$ 181,700$ for the first year of residency and for the second through the fourth year $\$ 86,828$ ( $\$ 181,700$ minus $\$ 94,872$ ). We have included this amount as income earned by a typical resident, which of course, includes the salary and benefits paid to residents during the four years of their residency.

\section{The Model- Net Present Value Calculation}

Net Present Value (NPV) is the difference between the present value of cash inflows and the present value of cash outflows. NPV is used in capital budgeting to analyze the profitability of a projected investment or project. The following is the formula for calculating NPV:

$$
N P V=\sum_{t=1}^{T} \frac{C_{t}}{(1+r)^{t}}-C_{0}
$$

Where:

$\mathrm{C}_{\mathrm{t}}=$ net cash inflow during the period $\mathrm{t}$, i.e., the revenue $\mathrm{Rt}$

$\mathrm{Rt}=\mathrm{W}+\mathrm{PSUB}+\mathrm{NPSUB}$ where $\mathrm{W}=$ Physician income, PSUB $=$ total GME subsidy, and NPSUB is PSUB minus revenue generated by physicians during residency training.

NPSUB $=$ net public subsidy. ${ }^{23}$ Net public subsidy is total subsidies, mostly Medicare, Medicaid and US Veteran's Administration payments minus revenue obtained from services supplied by senior residents.

$\mathrm{C}_{\mathrm{o}}=$ total initial investment cost of training to be a physician. $\mathrm{Co}=\mathrm{T}+\mathrm{F}$ where $\mathbf{T}$ is the cost of medical college tuition, and $\mathbf{F}$ is the foregone income during medical college and residency training.

$\mathbf{t}=$ number of time periods

$\mathbf{r}=$ the cost of capital or the discount rate. Most studies of this kind use 5\% (0.05) as this represents the long run interest rate on a relatively safe bond.

Time period $\mathbf{t}$ is the number of years we assumed physicians to remain in active practice. Most studies of this nature assume a typical physician to enter medical college at age $23^{24}$. We assumed that most physicians completed medical college at age 27 and residency training at age 31 . Further, we assumed physicians to remains in active practice until the age of 65 although there is some evidence that physicians

\footnotetext{
${ }^{23}$ Note: Most, if not all, other studies on physician NPV estimates do not include public funding of residency training.

${ }^{24}$ AAMC, Table A-6: Age of Applicants to U.S. Medical Schools at Anticipated Matriculation by Sex and Race/Ethnicity, 2013-2014 through 2016-2017. Accurate data on median age of entering medical college in 2007/8 academic year was not collected by AAMC. We use the median age for the academic year of 2013/14.
} 
tend to remain active longer than most members of the labor force. ${ }^{25}$ However, we decided to take the conservative approach and assume physicians will retire at age 65. Subtracting 31 from $65=34$ are the expected number of years of active practice.

For this study, we divided the 42 years of a physician's career, i.e., for the time they enter college to the time of their retirement into four periods. We assumed the 42 years of a physician's career to consist of 4 years for medical college, 4 years for residency and 34 years of the active service. In each period, we estimated the associated costs and revenues as follows. The first period is the 4 years in college where the medical student incurs direct and indirect costs (tuition and the opportunity costs of lost income for 4 years). Also, during the first period and there are no cash inflows from the medical services that students can provide. The second period is the first year of residency training where the resident physician has no direct training costs, receives a publicly funded subsidy for training, and has an opportunity cost of lost wages. During the second period, however, the resident has no income since the state does not issue a license to practice until the completion of the first year of residency.

The third period covers the second through the fourth year of residency training where the resident continues to receive publicly funded subsidies but also provides medical care services and incomes to the training hospital. During the third period the resident has no direct medical training costs, however there is an opportunity cost of lost wages.

Finally, the fourth period covers the years of active practice where the physician has only income from the provided medical services. We assume zero direct and indirect costs; no public subsidies and no opportunity costs now that the physician is assumed to be working full time. The estimation of these inflows and outflows has as follows.

\subsection{The Four Time Periods of the NPV}

Time-Period 1: Net Present Value Model for Medical College

$$
\text { NPV } 2007-2010=-\sum_{t=0}^{3} \frac{T+F}{(1+r)^{t}}
$$

\footnotetext{
${ }^{25}$ Burstein and Cromwell, Relative Incomes and Rates of Return for U.S. Physicians, 1984, Journal of Health Economics, assumed physicians retire at age 65 and a discount rate of 5\%. However, they note that the rate of return on investment in medical education is "quite sensitive to the time discount rate employed. At a 5 percent rate, assuming a fixed, age 65 retirement rate for all occupations reduces the return to medical education by 2.3 percentage points." The AMA states "that 16.2 percent of GPS were still in active practice over age 65 , working 45 hours per week."
} 
Table 2. Descriptive Statistics

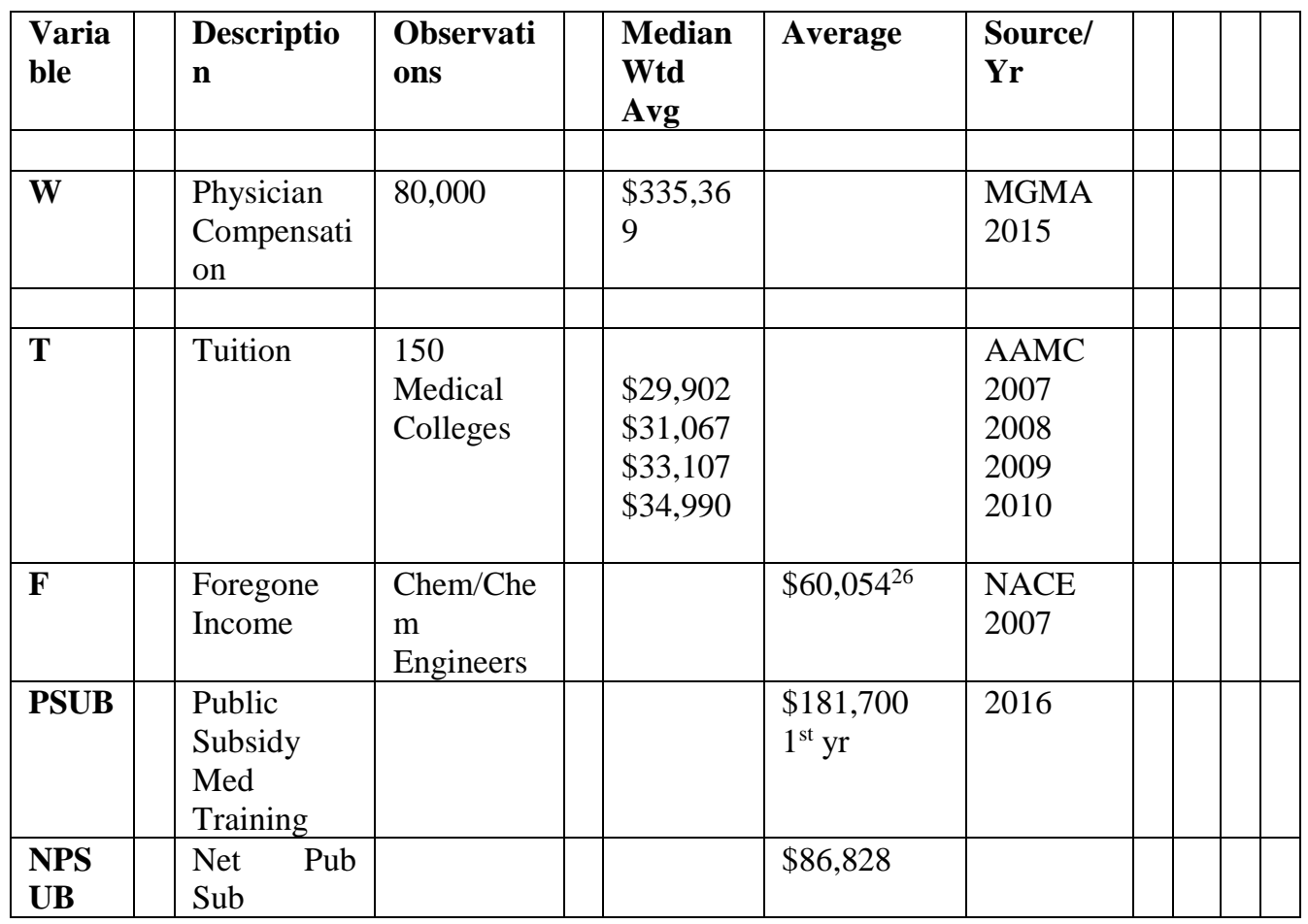

Where $\mathbf{T}$ is medical college tuition for the first four years of medical college and $\mathbf{F}$ is the estimated foregone income while in medical college. We have weighted average tuition data for each of the four years of medical college.

Data indicates that $\mathbf{F}$ increased by approximately 3.8 percent per year between 2007 and 2015 so we increased $\mathbf{F}$ by 3.8 percent for each year of medical college and residency training. The NPV for this period is negative as there are only costs and no income.

We estimated the cost of tuition for this four-year period by using the weighted average tuition from the AAMC survey of medical colleges and we added the cost of medical insurance. We used weighted average tuition because public medical colleges charge residents of the state a significantly lower tuition compared to nonresidents and private college tuition. The weighted average tuition, fees, and insurance for the four-year period from $2007 / 8$ to $1010 / 11$ was $\$ 29,902, \$ 31,067$, $\$ 33,107$ and $\$ 34,990$ respectively. We believe our estimates to be higher than the

${ }^{26}$ We estimate that $F$ increases $3 \%$ per year. 
real tuition because many medical colleges provide financial aid that was not available to us.

We estimate the forgone income $\mathbf{F}$ for the same period 2007/8 $-1010 / 11$ to be $\$ 60,054, \$ 62,336, \$ 64,705$, and $\$ 67,164$ respectively.

Therefore NPV $(2007-2010)=$ Negative $\$ 338,927$.

Time-Period 2: NPV Model for First Year of Residency

$\operatorname{NPV}(2011)=\sum_{t=0}^{1} \frac{\text { PSUB }-F}{(1+r)^{t}}$

During the first year of residency, the physician is not paying tuition, but is receiving a subsidy (including a salary). There is also a foregone income since during their first year of residency physicians are not yet licensed to practice medicine. In this case, PSUB is the subsidy physicians receive from Medicare, Medicaid and other sources (state aid and other funding sources received by training hospitals. In this case PSUB $=\$ 181,700$. Note that, $\mathbf{S}$, the stipend is zero because it is included in the public subsidy from Medicare, Medicaid, and VA GME payments to teaching hospitals. $\mathbf{F}$ is $\$ 69,716$ for 2011 .

Therefore NPV $(2011)=\$ 106,651(\mathrm{PV}$ of $\$ 111,984)$.

Time-Period 3: NPV Model for Residency Training Years 2 thru 4

$\operatorname{NPV}(2012-2014)=\sum_{t=5}^{7} \frac{\text { NPSUB }-F}{(1+r)^{t}}$

In this phase of training, the resident is generating financial resources in the form of minor surgery, consultations, and others. Thus, we estimated the PSUB for the four years of residency to be $\$ 181,700$ (We assume $\$ 181,700$ to be the amount per year) while the revenue generated by a typical second through fourth year resident $\$ 94,872$. Therefore, we estimated the net public subsidy to be $\$ 86,828$ ( $\$ 181,700$ $\$ 94,872=\$ 86,828)$. We count this net subsidy as implicit income NPSUB. We further assumed the revenue generated to increase $4 \%$ per year for the three years. F for the years 2012 through 2014 is $\$ 72,365, \$ 75,115$, and $\$ 77,969$ respectively.

Therefore NPV $(2012-2014)=\$ 51,148$. 
Time-Period 4: Net Present Value Model for a Practicing Physicians After all Training is Completed:

$$
\operatorname{NPV}(2015-2046)=\sum_{t=9}^{43} \frac{W-F}{(1+r)^{t}}
$$

W is the physician income or revenue (salary and benefits) for 2015 and is the weighted median salary of all specialties of physicians based on their representation in the sample of 33,000 physicians responding to the survey. The lower paying specialties such as internal medicine and general or family medicine composed about $40 \%$ of the compensation and specialty physicians about $60 \%$.

The median salary $W$ is $\$ 333,359$. Half of the physicians had more than $\$ 333,359$ in compensation before taxes while the other half had compensation less than $\$ 333,359$. We have to make an assumption about the future growth of physician income. Given the emphasis of federal policy to increase insurance coverage for those without health insurance and the fact that there is no apparent effort to increase adequately the number of medical college openings, we assume physician incomes will continue to grow. We assumed that both $\mathrm{W}$ and $\mathrm{F}$ grow at the same rate in order to calculate the NPV for period 4.

Finally, we calculated the total NPV for physicians as the sum of the NPVs from each of the four cash flow periods as follows:

Therefore NPV 2007-2010 + NPV 2011 + NPV 2012-2014 + NPV 2015-2049 = $\mathrm{NPV}-\$ 338,927+\$ 106,651+\$ 51,148+\$ 7,540,145=\$ 7,359,017$

NPV without the GME Subsidy (call it NPVW) Since most studies calculating NPV do not count the subsidies to teaching hospitals - the federal subsidies to GME, we recalculated periods 2 and 3 of the model by eliminating the implicit income to resident physicians. The model then becomes as follows:

e.g., NPVW $(2011-2014)=\sum_{t=5}^{8} \frac{S-F}{(1+r)^{t}}$

$\operatorname{NPV}(2011-2014)=\sum_{t=5}^{8} \frac{S-F}{(1+r)^{t}}$

Where $\mathbf{S}$ represents the mean value of the stipends resident physician receives for four (4) years ${ }^{27}$. Based on AACM data, the value of $\mathbf{S}$ is $\$ 49,651$ for the first year, $\$ 51,428$ for the second year, $\$ 53,454$ for the third year, and $\$ 55,750$ for the fourth year.

${ }^{27}$ Source: AAMC Survey of Resident/Fellow Stipends and Benefits Nationwide, Table. 
The values for $\mathrm{F}$ are $\$ \$ 69,716$ for $2011, \$ 72,365$ for $2012, \$ 75,115$ for 2013 , and $\$ 77,969$ for 2014. Therefore, NPVW (2011-2014) $=-75091$

Finally, we estimated the total NPV for physicians for the four periods without the GME subsidy to be:

NPV 2007-2010 + NPV 2011-2014 + NPV 2015-2049 = NPV (2007-2049)

$-\$ 338,927+-\$ 75,091+\$ 7,359,017=\$ 6,945,000$

\section{Summary Findings}

We find that the net present value (NPV) of lifetime income for U.S. physicians who entered medical college in 2007 and finished training in 2015 are expected to have a NPV of lifetime earnings of approximately $\$ 7$ million. We based this income stream on the assumption that the median weighted average before tax earnings of all specialties was $\$ 333,000$ in 2015 (Table 3).

Table 3. Medium Compensation per specialty

Specialty

Anesthesiology

Cardiology: Invas-Intervent

Critical Care Intensivist

Dermatology

Emergency Medicine

Family Medicine/ w OB

Family Medicine/ wo OB

Family Medicine Only

Gastroenterology

Hematology/Oncology

Hospitalist:

Medicine

Infectious Disease

Internal Medicine

Internal

Ambulatory

Nephrology

Neurology

Obstetrics/Gyn/Gen

Ophthalmology
Median Compensation - 2015

\#

Observations

$\$ 453,687$

229

587,500

811

398,173

211

457,419

366

311,859

902

223,893

703

230,456

5532

221,322

573

529,223

993

450,000

713

278,471

2856

258,218

288

247,319

4018

233,494

624

322,024

303

286,008

829

330,696

2154

407,272

of

西




Orthopedic Surgery-gen
Orthopedic Surgery: Spts
Med
Otorhinolaryngolony
Pediatrics- Gen
Pediatrics: Neonatal Med
Physiatry-Phys Med\&Rehab
Podietry/Gen
Psychiatry:Gen
Pulmonary Med/Gen
Pulmonary Med/Crit Care
Radiation Oncology
Radiology/Diagnostic
Rheumatology
Surgery/Gen
Surgery/Cardiovascular
Surgery/Neurological
Surgery/Plas\&Reconstruction
Surgery/Vascular
Urgent Care
Urology

576,677

841

$597,347 \quad 226$

$444,348 \quad 486$

$231,637 \quad 2640$

$323,311 \quad 247$

$276,510 \quad 340$

$237,098-222$

$255,543 \quad 566$

$358,035 \quad 260$

$397,335 \quad 353$

$500,000 \quad 241$

$478,165 \quad 910$

$255,560 \quad 302$

409,665

$717,987 \quad 270$

$772,914 \quad 338$

$496,243 \quad 217$

$493,385 \quad 261$

$239,536 \quad 468$

$452,294 \quad 620$

Total

33,573

weighted median compensation $=\$ 335,369$

$=$ SUMPRODUCT $(\mathrm{F} 8: \mathrm{F} 45, \mathrm{~B} 8: \mathrm{B} 45) / \mathrm{SUM}(\mathrm{F} 8: \mathrm{F} 45)$

The sample size was approximately 34,000 physicians. Approximately 20,000 of these physicians had median earnings $\left(50^{\text {th }}\right.$ percentile) of less than $\$ 300,000$ and approximately 11,000 had median earnings of between $\$ 400,000$ and $\$ 600,000$ in 2015.

Obviously not all physicians will expect to earn an NPV of \$7 million from their investment in medical education. Primary care physicians tend to have lower NPV's compared to Cardiology or Radiology for example. However, specialists tend to have longer residency training periods in the range of 5 to 6 years. Our NPV estimates are consistent with the finding of other researchers in this area. 
Nicholson $^{28}$ found that between 1986 and 1998 many specialists had very high NPV's. For example, he found that Radiologist, Orthopedic Surgery and General Surgery specialists had NPV's in the $\$ 8$ million range ${ }^{29}$, while General Internal Medicine had NPV's of approximately $\$ 4.0$ million. ${ }^{30}$

\section{Policy Implications}

The findings in almost all the research regarding incomes of physicians indicate that this industry is earning high rates of return on investment in medical education over a very long period. Normally this is not the case based on market criteria. When high rates of return exist in an industry entry will eventually occur that will bring down the high earnings. However, this is not the case in many areas of the medical industry.

What are the blockages that impede entry? Medical colleges face barriers in expanding capacity due to accreditation standards so that qualified students can enter this profession. It appears that the federal government, through the Department of Education, has the authority to designate what organizations have the authority to accredit medical colleges. In the field of medicine, the Department of Education has designated the Liaison Committee on Medical Education (LCME) as the only accrediting body to accredit medical colleges. It turns out that the LCME consists of members of the American Medical Association and the American Association of Medical Colleges.

It appears that there is a long waiting list of qualified students willing to pay tuition and enter medical college and this situation has existed for many years. However, the availability of open slots is not growing nearly as fast. With respect to entrance into the more financially rewarding medical specialties there appears to be another blockage. Nicholson has described a number of reasons that the incomes of nonprimary care physicians will continue to be above the market clearing level. According to Nicholson, the answer may lie in the regulatory structure of the way medical college graduates are admitted to GME in high paying specialties such as radiology or pediatric surgery programs.

According to Nicholson, "the Accreditation Council for Graduate Medical Education (ACGME), a private non-profit organization that is responsible for overseeing residency training, may be pompously limiting residency positions in order to secure economic rents for practicing physicians." 31 The American Medical Association and

\footnotetext{
${ }^{28}$ Sean Nicholson, Barriers to Entering Medical Specialties, 2003, University of Pennsylvania and the National Bureau of Economic Research.

${ }^{29}$ Nicholson's findings are based on 1998 dollars. We adjusted to compare with 2015 prices.

${ }^{30}$ Nicholson, Table 1., pp. 30.

${ }^{31}$ Nicholson, p. 14.
} 
the American Board of Medical Specialties are sponsoring organizations of the ACGME. The ACGME allows one of its committees, the Residency Review Committee (RRC) to establish policies that determine accreditation standards of the 26 residency specialists. If a teaching hospital wants to establish or expand a residency program in, say, Radiology, it must gain permission for the RRC. As Nicholson states, this approval process has the appearance of a "fox guarding the chicken coop". ${ }^{32}$ Thus, the ACGME has control over the flow of physicians into specialties because a physician cannot practice the specialty without gaining a license for the states and the states require the physician to be a graduate of an ACGMGE accredited residency-training program. This may explain why the incomes of Internal and Family physicians have lower incomes than non-primary physicians as the over-flow of those who would like to practice non-primary medicine have to go into these residency slots.

\section{References:}

Association of American Medical Colleges. 2014. Annual Student Tuition and Fees Report. AAMC, https://services.aamc.org/tsfreports/

Association of American Medical Colleges. 2013. Medical School Applicants, Enrollment Reach All-time Highs, https://www.aamc.org/newsroom/newsreleases/358410/20131024.html

Association of American Medical Colleges 2016. Report New Research Confirms Looming Physician Shortage.

Association of American Medical Colleges. 2014. Survey of Resident/Fellow Stipends and Benefits Report. https://www.aamc.org/download/412558/data/201 4stipendsurveyreportfinal.pdf

Association of American Medical Colleges. 2018. U.S. Medical School Matriculants, 20082015, Race/Ethnicity Self-Identification Counts With a Matriculant Able to Appear in More than One Race/Ethnicity Category.

Ben, A., Robbins, R., Pindiprolu, S. and Goodman, A. 2014. The Cost of Training Internal Medicine Residents in the U.S. American Journal of Medicine, 127(10), October.

Borad, N. 2015. The Value of Medical Education in the United States. Unpublished paper, The College of New Jersey, April 10.

Burstein, P. and Cromwell, J. 1985. Relative incomes and rates of return for U.S. physicians. Journal of Health Economics, 4(1), 63-78.

Committee on the Governance and Financing of Graduate Medical Education. 2014. Board of Health Care Services; Institute of Medicine, Graduate Medical Education that Meets the Nation's Health Needs, Ed. JEden, J., Berwick, D. and Wilensky, G., Washington, D.C. National Academies Press.

Dorsey, E.R., Nincic, D. and Schwartz, J.S. 2006. An evaluation of four proposals to reduce the financial burden of medical education. Academic Medicine 81(3), 245-251.

Feldman, R.1978. The Supply of Medical School Applicants and the Rate of Return to Training. The Quarterly Review of Economics and Business: Journal of the Midwest Economics Association, 18(1), 91-98.

Leffler, K.B. 1978. Physician Licensure: Competition and Monopoly in American Medicine. Journal of Law and Economics, 21(1), 165-186.

\footnotetext{
${ }^{32}$ Nicholson, p. 15.
} 
Leigh, J.P., Tancredi, D., Jerant, A. and Kravitz, R.L. 2010. Physician Wages Across Specialties: Informing the Physician Reimbursement Debate. JAMA Internal Medicine, 170(19), 1728-1734.

Kaiser Family Foundation. 2014. Total Health Care Employment, http://kff.org/other/stateindicator/total-health-care-employment/16

Medical Group Management Association. 2016. Provider Compensation and Production Report.

MedScape. 2014. Physician Compensation Report, http://www.medscape.com/sites/public/physician-comp/2014

National Association of Colleges and Employers. 2013. Salary Survey. NACE, https://careers.washington.edu/sites/default/files/all/editors/docs/2013 - september-salary-survey.pdf

Nicholson, S. 2003. Barriers to Entering Medical Specialties. NBER and The Wharton School, University of Pennsylvania.

Rampell, C. 2013. How Medicare Subsidizes Doctor Training, NY Times, December 17.

Roth, N. 2009. The Costs and Returns to Medical Education. UC Berkeley Department of Economics, https://www.econ.berkeley.edu/sites/default/files/roth_nicholas.df

Stoller, J., Pratt, S., Stanek, S., Zelenock, G., Nazzal, M. 2016. Financial Contributin of Residents When Billing as "Junior Associates" in the "Surgical Firm". Journal of Surgical Education, 73(1), 85-94.

Youngclaus, J. and Fresne, A.J. 2012. Physician Education Debt and the Cost to Attend Medical School. https://www.aamc.org/download/328322/data/statedebtre.

U.S. Department of Health and Human Services. 2015. Health Insurance Marketplace 2015 Open Enrollment Period: March Enrollment Report. ASPE Issue Brief. http://aspe.hhs.gov/health/reports/2015/MarketPlaceEnrollment/Mar2015/ib_2015m ar_enrollment.pdf

U.S. Department of Health and Human Services. 2008. Health Resources and Services Administration, Bureau of Health Professions, "Physician Workforce: Projections and Research into Current Issues Affecting the Supply and Demand, December.

U.S. Government Accountability Office. 2009. Graduate Medical Education: Trends in Training and Student Debt, 09-438R, May 4. 